\title{
On Distribution of Filamentous-Cluster Organisms (Krassilnikoviae) in Sea and Ocean Depths
}

\author{
By A. E. KRISS AND I. N. MITSKEVICH \\ Department of Marine Microbiology, Institute of Microbiology, \\ Academy of Sciences, Moscow, U.S.S.R.
}

(Received 26 April 1960)

\section{SUMMARY}

The investigations carried out make it possible to conclude that filamentouscluster organisms (Krassilnikoviae) rather form accumulations-layers at certain depths than get diffusely distributed in the sea and ocean water column. Possibly these layers occur at the junctions of water masses of different densities. The filamentous-cluster organisms have been found in all geographic zones of the world ocean, from Polar latitudes down to the equator.

It was established (Kriss \& Mitskevich, 1959) that peculiar filamentous-cluster organisms occurring in sea and ocean water could be found mature and in considerable quantities on immersed slides within $6 \mathrm{hr}$. after these had been submerged

Table 1. The rate of appearance of filamentous-cluster organisms on slides after the latter were immersed into the depths of the Black Sea

\begin{tabular}{|c|c|c|c|c|c|c|c|}
\hline $\begin{array}{l}\text { Depth } \\
\text { slide }\end{array}$ & & & Duration o & of exposure of & slides & & \\
\hline (m.) & $2.75 \mathrm{hr}$. & 2 hr.* & $1 \mathrm{hr} . *$ & 30 min.* & 15 min. & $5 \mathrm{~min}$. & $5 \mathrm{~min}$. \\
\hline 25 & $\begin{array}{l}\text { Single } \\
\text { individuals }\end{array}$ & $\begin{array}{l}\text { Single } \\
\text { individuals }\end{array}$ & $\begin{array}{l}\text { Single } \\
\text { individuals }\end{array}$ & $\begin{array}{l}\text { Single } \\
\text { individuals }\end{array}$ & - & . & . \\
\hline 100 & Interlace & Interlace & Interlace & Interlace & Interlace & Interlace & Interlace \\
\hline 200 & Interlace & Interlace & Interlace & Interlace & . & . & . \\
\hline 300 & Interlace & Interlace & Interlace & Interlace & . & . & . \\
\hline 500 & $\begin{array}{l}\text { Single } \\
\text { individuals }\end{array}$ & . & Interlace & Interlace & . & . & . \\
\hline 750 & Interlace & Interlace & Interlace & Inte & . & . & - \\
\hline 1000 & Interlace & Interlace & Interlace & Interlace & . & . & . \\
\hline
\end{tabular}

* This exposure is for the upper slide; for the other slides it is much longer. In case of simultaneous immersion of slides to various horizons of the sea-water column the time difference between upper-slide exposure and lower-slide exposure (at $1000 \mathrm{~m}$.) is $c .1 \mathrm{hr}$.

to various depths. Taking into account the absence of filamentous-cluster organisms on filters through which were passed 20,30 and $50 \mathrm{ml}$. water samples taken from the same horizons where filamentous-cluster organisms had been found on the slides, it was concluded that the organisms had developed on the slides and had not attached themselves from the water as ready-formed filaments with heads. However, the formation rate of these organisms seemed surprisingly high and therefore the investigation was continued. In the open part of the Black Sea slides were 
immersed to depths of $25,100,200,300,500,750$ and $1000 \mathrm{~m}$. and exposed from 0.5 to $2.75 \mathrm{hr}$. Table $\mathrm{I}$ shows that even by a short exposure $(30-60 \mathrm{~min}$.) not infrequently a dense accumulation of filamentous-cluster organisms was found. These short time periods seemed obviously insufficient for filaments with heads to form on the slides. It became clear from the following experiment that single individuals or accumulations and interlacings of filamentous-cluster organisms got mechanically attached to the immersed slides. Slides were immersed to a depth of $100 \mathrm{~m}$. and promptly removed. Although the immersion and removal of the slides took only 5 min., filaments with heads, either singly or in the form of accumulations or interlaced arrangements, were found on them. At the same time it became evident that samples taken by a bathometer from various depths in the Black Sea did not show filamentous-cluster micro-organisms even in such volumes as 500 or $1000 \mathrm{ml}$. This was proved by passing these volumes of water through membrane ultrafilters and examining them by microscopy.

These data make it possible to assume that, as a rule, filamentous-cluster organisms form layers and accumulations at certain depths rather than being diffusely distributed in the water column of seas and oceans. It is quite sufficient for a slide to pass through a layer or accumulation of this kind for it to collect a considerable number of filamentous-cluster organisms which are not infrequently interlaced in the form of long strings visible to the naked eye.

The turning of the cable exercised a negative influence on the 'catch', particularly during quick immersion. This was proved by immersing slides $(12 \times 14 \mathrm{~cm}$.) in a horizontal position, the slides being fixed to the cable with the aid of rubber holders. It was observed that during immersion and removal the slides turned from side to side. Obviously, this turning of the cable in the water breaks up the accumulations of filamentous-cluster organisms, judging by the relatively small quantity of these organisms found on the large slides as compared with small slides.

It would appear that in sea and ocean depths there are formed more than one layer of filamentous-cluster organisms, since fairly frequently (Kriss \& Mitskevich, 1959, Table 1) their quantity found in deeper horizons was greater than that found in less deep horizons. Possibly these layers occur at the junctions of water masses of different densities. This might account for relatively high quantities of filamentouscluster organisms at the upper and lower boundaries of the Atlantic Current in the region of the North Pole.

A wide distribution of filamentous-cluster organisms in the world oceans has been confirmed by investigations carried out in the central part of the Pacific Ocean (expedition on S.S. Vitijaz, 1958) and along $30^{\circ} \mathrm{W}$. in the Atlantic Ocean (expedition on S.S. Lomonosov, 1959). By the methods described earlier, and in addition to the data already published (Kriss \& Mitskevich, 1959) it was established that filamentous-cluster organisms occurred at various depths of the ocean water column in subtropic and tropic-equatorial areas (Table 2). Thus, their geographic area in the world oceans extends from Polar latitudes to the equator.

\section{REFERENCE}

Kriss, A. E. \& Mrtskevich, I. N. (1959). Krassilnikoviae: A new class of micro-organisms found in sea and ocean depths. J. gen. Microbiol. 20, 1. 